\title{
Co-targeting AR and HSP90
} suppresses prostate cancer cell growth and prevents resistance mechanisms

\author{
Margaret M Centenera, ${ }^{1,2}$, Sarah L Carter ${ }^{1}$, Joanna L Gillis ${ }^{1,2}$, \\ Deborah L Marrocco-Tallarigo', Randall H Grose ${ }^{2}$, Wayne D Tilley ${ }^{1}$ and Lisa M Butler ${ }^{1,2}$
}

'Dame Roma Mitchell Cancer Research Laboratories, Adelaide Prostate Cancer Research Centre and Freemason's Foundation Centre for Men's Health, School of Medicine, University of Adelaide, Adelaide, Australia

${ }^{2}$ South Australian Health and Medical Research Institute, PO Box 11060, Adelaide, South Australia 5001, Australia
Correspondence should be addressed to L M Butler Email

lisa.butler@adelaide.edu.au

\begin{abstract}
Persistent androgen receptor (AR) signaling in castration resistant prostate cancer (CRPC) underpins the urgent need for therapeutic strategies that better target this pathway. Combining classes of agents that target different components of AR signaling has the potential to delay resistance and improve patient outcomes. Many oncoproteins, including the AR, rely on the molecular chaperone heat shock protein 90 (Hsp90) for functional maturation and stability. In this study, enhanced anti-proliferative activity of the Hsp90 inhibitors 17-allylamino-demethoxygeldanamycin (17-AAG) and AUY922 in androgen-sensitive and CRPC cells was achieved when the agents were used in combination with AR antagonists bicalutamide or enzalutamide. Moreover, significant caspasedependent cell death was achieved using sub-optimal agent doses that individually have no effect. Expression profiling demonstrated regulation of a broadened set of AR target genes with combined 17-AAG and bicalutamide compared with the respective single agent treatments. This enhanced inhibition of AR signaling was accompanied by impaired chromatin binding and nuclear localization of the AR. Importantly, expression of the AR variant $A R-V 7$ that is implicated in resistance to $A R$ antagonists was not induced by combination treatment. Likewise, the heat shock response that is typically elicited with therapeutic doses of Hsp90 inhibitors, and is a potential mediator of resistance to these agents, was significantly reduced by combination treatment. In summary, the co-targeting strategy in this study more effectively inhibits AR signaling than targeting AR or HSP90 alone and prevents induction of key resistance mechanisms in prostate cancer cells. These findings merit further evaluation of this therapeutic strategy to prevent CRPC growth.
\end{abstract}
Key Words
- prostate cancer
- heat shock protein
androgen receptor
- combination

Endocrine-Related Cancer (2015) 22, 805-818

\section{Introduction}

Androgen deprivation therapy (ADT) is used palliatively to control tumor growth and metastasis in men with locally advanced prostate cancer (Labrie 2011). Despite an initial response to ADT, the majority of patients will inevitably progress to castrate-resistant prostate cancer (CRPC) that is not curable by current treatments. CRPC 
develops as prostate cancer cells adapt to a low androgen environment through a range of resistance mechanisms that are predominantly mediated by alterations to androgen receptor (AR) signaling (Karantanos et al. 2013, Maughan \& Antonarakis 2015). These include AR overexpression or amplification (Chen et al. 2008), acquisition of gain-of-function point mutations in the AR gene (Buchanan et al. 2001), intra-tumoral androgen biosynthesis (Cai \& Balk 2011) or emergence of C-terminally truncated AR variants (ARVs) that are constitutively nuclear and active (Sun et al. 2010, Li et al. 2011). This adaptation to therapy-mediated selection pressure is well recognized with the use of molecularly targeted cancer therapies (Izar et al. 2013) and has led to the growing paradigm that ablating a target with a single agent is unlikely to result in sustained growth inhibition. Recently, an integrative clinical genomics analysis of 150 metastatic CRPC cases revealed that $71.3 \%$ harbored aberrations in AR signaling (Robinson et al. 2015). This high frequency clearly demonstrates the continued reliance of CRPC on AR signaling and provides a biological rationale for the development of AR-targeted combination therapy. We hypothesize that using agents with different mechanisms of action, to simultaneously inhibit both the expression and activity of AR, will minimize the likelihood of an adaptive response and thereby improve disease outcomes.

Functional maturation of the AR protein is a critical step in the androgen signaling axis that can be targeted through inhibition of the molecular chaperone heat shock protein 90 (Hsp90) (Centenera et al. 2013). Molecular chaperones are required for the stabilization and activity of a diverse group of proteins, known as clients, which includes steroid receptors, transcription factors and protein kinases (Trepel et al. 2010). Importantly, Hsp90 folds the AR into the correct conformation for stable, high affinity ligand binding (Pratt \& Toft 1997). As the chaperone activity of Hsp90 is ATP-dependent, most Hsp90 inhibitors are targeted to the conserved ATPbinding site and cause ubiquitin-mediated proteasomal degradation of more than 200 client proteins (Workman et al. 2007). The first Hsp90 inhibitor to enter clinical trials was the ansamycin derivative 17-allylamino-demethoxygeldanamycin (17-AAG). In pre-clinical studies, 17-AAG degraded the AR and other proteins (Her2, Akt, Bcr-Abl and Raf-1) implicated in prostate carcinogenesis, leading to cell cycle arrest and inhibition of prostate cancer cell growth in vitro and in vivo (Solit et al. 2002, Vanaja et al. 2002, Williams et al. 2007). Unfortunately, 17-AAG did not show its predicted clinical efficacy as a single agent in
CRPC, due to toxicity and poor pharmacodynamic properties that prevented therapeutic doses being achieved (Banerji et al. 2005, Heath et al. 2008, Ramanathan et al. 2010). While more potent inhibitors such as AUY922 are currently being developed and show promise as single agents (Samuel et al. 2010, Centenera et al. 2012), recent evidence of additive or synergistic activity between 17-AAG and cytotoxic agents or specific molecular therapeutics provides a promising new avenue of clinical development for this drug (Lu et al. 2012). In preclinical prostate cancer studies, 17-AAG or AUY922 combined with ionizing radiation has demonstrated supra-additive reductions in tumor growth and clonogenicity (Enmon et al. 2003, Ochel \& Gademann 2006, Gandhi et al. 2013). Likewise, AUY922 sensitized CRPC prostate cancer cells lines to treatment with docetaxel chemotherapy (Ku et al. 2014). In a Phase I trial of 17-AAG plus docetaxel, $25 \%$ of the patients with prostate cancer exhibited a prostate-specific antigen (PSA) decline of $\geq 20 \%$ (Iyer et al. 2012).

AR antagonists compete with androgens for binding to the AR. The AR antagonist bicalutamide is typically used in combination with ADT to inhibit signaling from residual circulating androgens in a strategy known as combined androgen blockade (CAB). $\mathrm{CAB}$ prolongs survival in both locally advanced and metastatic disease, particularly when administered as first-line systemic therapy (Labrie 2011); however, AR antagonists and ADT both essentially act to prevent ligand activation of the AR and patients inevitably develop resistance. The new generation antagonist enzalutamide also targets the AR ligand-binding domain but was specifically selected to have anti-tumor activity in prostate cancer cells that overexpress the AR (Tran et al. 2009) as this is a key aberration in CRPC (Robinson et al. 2015) and an important mechanism of resistance to androgen targeting agents (Chen et al. 2004). AR antagonists are a rational choice for use in combination with Hsp90 inhibitors due to the unique chaperone dependence of antagonist-bound AR. Several studies have demonstrated that bicalutamide stabilizes the interaction between AR and Hsp90, which prevents AR from acquiring its active state (Veldscholte et al. 1992, Kuil et al. 1995, Georget et al. 2002). As Hsp90 dissociates less readily from AR when bound to bicalutamide, compared to androgens, we propose that the use of bicalutamide maintains the AR as a vulnerable target for degradation by Hsp90 inhibitors. The aim of this study was to evaluate whether co-targeting Hsp90 and AR can achieve a better blockade of androgen signaling to enhance prostate cancer cell death.

Published by Bioscientifica Ltd. 


\section{Materials and methods}

\section{Cells and reagents}

LNCaP, 22Rv1, C4-2B and PC-3 human prostate carcinoma cells were purchased from the American Type Culture Collection (Rockville, MD, USA). All cell lines underwent verification by short-tandem repeat profiling in 2010 by CellBank Australia. LNCaP, 22Rv1 and C4-2B cells were maintained in RPMI 1640 supplemented with 10\% fetal bovine serum (FBS), and PC-3 cells were supplemented with 5\% FBS. The National Cancer Institute provided 17-AAG, AUY922 was provided by Novartis, bicalutamide was purchased from Sigma and enzalutamide was purchased from Selleckchem (Houston, TX, USA). All drugs were dissolved in dimethylsulfoxide (DMSO). Hsp27 (HPA000497) antibody was purchased from Sigma-Aldrich Co., Hsp70 (ADI-SPA-812) antibody from Enzo Life Sciences (Farmingdale, NY, USA), Hsp90 (SC-7947) and AR N-20 (SC816) antibodies from Santa Cruz Biotechnology (Dallas, TX, USA), $\alpha$-tubulin (05-829) antibody from Millipore (Billerica, MA, USA) and Histone H3 acetyl K27 (ab4729) antibody from Abcam (Cambridge, MA, USA). HRP-conjugated secondary antibodies were obtained from DAKO (Carpinteria, CA, USA). The tetrapeptide caspase inhibitor z-VAD-fmk was purchased from Calbiochem (Alexandria, NSW, Australia).

\section{Measurement of cell viability}

Cells were seeded in triplicate in 24-well plates at a density of $2.5 \times 10^{4}$ cells per well in RPMI medium containing $5 \%$ (PC-3) or 10\% (LNCaP, C4-2B, 22Rv1) FBS. Cells were treated as indicated for 4 days and counted as previously described (Centenera et al. 2012). The caspase inhibitor z-VAD-fmk $(50 \mu \mathrm{M})$ was included for the duration of the relevant experiments.

\section{Quantitation of drug synergy}

The combination index (CI) theorem of Chou-Talalay (Chou \& Talalay 1984) was used to quantify drug interactions with CompuSyn software (ComboSyn, Inc., Paramus, NJ, USA). This method uses the equation $A c / A e+$ $B c / B e=C I$ to determine the interaction between two drugs. $A c$ and $B C$ represent the concentration of drugs $A$ and $B$ used in the combination, whereas $A e$ and $B e$ represent the concentration of drugs A and B that produced the same magnitude of effect when administered alone. The resulting $\mathrm{CI}$ quantitatively defines drug synergy $(\mathrm{CI}<1)$, antagonism $(\mathrm{CI}>1)$ and additive effects $(\mathrm{CI}=1)$.

\section{Cell cycle analysis}

C4-2B cells were plated in six-well plates at a density of $1.5 \times 10^{5}$ per well in RPMI supplemented with $10 \%$ FBS. Two wells were used per treatment and all treatments were performed in triplicate. Cells were treated as indicated for $72 \mathrm{~h}$ then fixed as described previously (Centenera et al. 2012). Cell cycle analysis was performed on the LSRFortessa X-20 (BD Biosciences, Franklin Lakes, NJ, USA) running BDFACSDiva version 8.0 software (BD Biosciences) to generate frequency histograms.

\section{Microarray and pathway analysis}

LNCaP cells in six-well plates were treated as indicated for $6 \mathrm{~h}$. Six replicates were prepared per treatment. Total RNA was extracted using TRIzol reagent (Invitrogen), and integrity was analyzed with an Agilent Systems Bioanalyser (Santa Clara, CA, USA). Microarray analysis was performed at the Adelaide Microarray Centre. Briefly, $300 \mathrm{ng}$ of total RNA was labelled using the Affymetrix WT Sense Target labeling assay as per the manufacturer's instructions (Affymetrix, Inc., Santa Clara, CA, USA, p/n 701880). Samples were hybridized to Affymetrix Human Gene 1.0 ST Arrays for $17 \mathrm{~h}$ at $45^{\circ} \mathrm{C}$ prior to washing, staining and scanning. Data was analyzed with Partek Genomics Suite (Partek Inc., St. Louis, MO, USA). Differential gene expression was assessed by ANOVA with the $P$ value adjusted using step-up multiple test correction (Benjamini $\&$ Hochberg 1995) to control the false discovery rate (FDR). Adjusted $P$ values $<0.05$ were considered significant. Cluster and Treeview algorithms were used to generate self-organizing maps of the gene expression data sets (Eisen et al. 1998). Gene pathway analysis was conducted using core analysis in the Ingenuity Systems program (Ingenuity Systems, Redwood City, CA, USA) to identify molecular and cellular functions and canonical pathways that were enriched by the combination treatment. Differentially expressed genes were also analyzed for enriched gene ontology (GO) groups using the Database for Annotation, Visualization and Integrated Discovery (DAVID) (http:// david.abcc.ncifcrf.gov/; Huang da et al. 2009). Genes with a minimal twofold change and $P<0.05$ were included for analysis and the background gene set comprised of all genes on the Affymetrix Human GeneChip ST 1.0 array.

\section{Quantitative real-time PCR}

Microarray results were validated using an independently generated sample set by real-time PCR (RT-qPCR).

Published by Bioscientifica Ltd 
RNA $(1 \mu \mathrm{g})$ was DNAse treated with Turbo DNA Free (Ambion, Carlsbad, CA, USA) and reverse transcribed using iScript cDNA Synthesis Kit (Bio-Rad). RT-qPCR was performed with a 1:10 dilution of cDNA using SYBR green (Bio-Rad) on a CFX384 Real-Time System (Bio-Rad) with three-step amplification for 40 cycles. Gene expression is presented relative to L19 and GUSB as suggested by GeNorm (Vandesompele et al. 2002). Primer sequences are listed in Supplementary Table 1, see section on supplementary data given at the end of this article.

\section{Western blotting}

LNCaP cells were seeded in six-well plates at a density of $4 \times$ $10^{5}$ cells per well and allowed to attach for $24 \mathrm{~h}$ before being treated as indicated. Western blotting on whole cell extracts was performed as previously described (Centenera et al. 2012).

\section{Visualization of green fluorescent protein-tagged AR}

PC-3 cells were simultaneously seeded and transfected in sixwell plates containing $20 \mathrm{~mm}$ round glass coverslips. Cells were seeded at a density of $5 \times 10^{5}$ cells per well in phenol red free (PRF)-RPMI 1640 and transfected with $10 \mu \mathrm{g}$ pEGFP-ARwt using Lipofectamine 2000 (Life Technologies). After $24 \mathrm{~h}$, cells were treated for $4 \mathrm{~h}$ with RPMI 1640 supplemented with $10 \%$ FBS containing DMSO or combination treatment, $20 \mathrm{nM}$ 17-AAG $+2.5 \mu \mathrm{M}$ bicalutamide, or PRF-RPMI supplemented with 10\% dextran coated charcoal-treated FBS (dccFBS) containing vehicle (ethanol) or $10 \mathrm{nM} 5$-alpha-dihydrotestosterone (DHT). Cells were fixed in ice-cold methanol and immunostained with $\alpha$-tubulin primary antibody (1:100) for $1 \mathrm{~h}$, then Alexa Fluor 488 goat anti-mouse secondary antibody (1:400) for $1 \mathrm{~h}$ in the dark. Cells were mounted with ProLong Gold antifade reagent containing DAPI (Molecular Probes, Carlsbad, CA, USA). Slides were analyzed by the Confocal Microscopy Core Facility at the South Australian Health and Medical Research Institute on a Leica TCS SP8X/MP multifoton confocal microscope on an inverted DMI6000 microscope body with a resonance scanner $(12 \mathrm{kHz})$, coupled with a Ludin Cube/Box/Brick environmental control system. Analysis of fluorescent images was performed using ImageJ version 3.91 software.

\section{Subcellular fractionation}

LNCaP cells were seeded in PFR-RPMI 1640 supplemented with $10 \%$ dccFBS at a density of $8 \times 10^{5}$ cells per $10 \mathrm{~cm}$ plate. After 3 days the cells were treated for $4 \mathrm{~h}$ with RPMI containing $10 \%$ FBS containing DMSO or combination treatment, $20 \mathrm{nM}$ 17-AAG $+2.5 \mu \mathrm{M}$ bicalutamide, or PRFRPMI containing 10\% dccFBS containing vehicle (ethanol) or $10 \mathrm{nM}$ DHT. Protein interactions were crosslinked with a $1 / 10$ volume of fresh formaldehyde solution $(50 \mathrm{mM}$ HEPES-KOH, $100 \mathrm{mM} \mathrm{NaCl}, 1 \mathrm{mM}$ EDTA, $0.5 \mathrm{mM}$ EGTA, $11 \%$ formaldehyde). Cells were washed in PBS and resuspended in lysis buffer (LB) 1 (50 mM HEPES-KOH, $\mathrm{pH}$ 7.5; 140 mM NaCl; 1 mM EDTA; 10\% glycerol; 0.5\% NP-40 or Igepal CA-630; $0.25 \%$ Triton X-100). The cytoplasmic fraction was taken after centrifuging at $10,000 \boldsymbol{g}$ for $10 \mathrm{~s}$. The pellet was washed in $1 \mathrm{ml} \mathrm{LB} 2$ (10 mM Tris-HCL, pH 8.0; $200 \mathrm{mM} \mathrm{NaCl} ; 1 \mathrm{mM}$ EDTA; $0.5 \mathrm{mM}$ EGTA) and nuclear fraction was obtained by resuspending and sonicating the pellet in LB3 (10 mM Tris- $\mathrm{HCl}, \mathrm{pH} 8 ; 100 \mathrm{mM} \mathrm{NaCl} ; 1 \mathrm{mM}$ EDTA; $0.5 \mathrm{mM}$ EGTA; $0.1 \% \mathrm{Na}$-Deoxycholate; $0.5 \%$ $\mathrm{N}$-lauroylsarcosine). Fractions were centrifuged and equivalent volumes of supernatant were separated by SDS-PAGE to assess AR location by probing with AR N-20 (1:1000). Appropriate subcellular fractionation was assessed using the cytoplasmic marker $\alpha$-tubulin (1:20 000) and the nuclear marker H3 acetyl K27 (1:1000).

\section{Chromatin immunoprecipitation}

LNCaP cells were seeded in $15 \mathrm{~cm}$ plates at a density of $3 \times 10^{6}$ cells in RPMI 1640 containing 10\% dccFBS. Cells were cultured for 3 days, then treated for $4 \mathrm{~h}$ with vehicle or combined 17-AAG and bicalutamide in RPMI 1640 containing 10\% FBS. Chromatin immunoprecipitation (ChIP) was performed as described previously (Schmidt et al. 2009) with the following modifications. Samples were immunoprecipitated overnight with ARN-20x (Santa Cruz816x) or Normal Rabbit IgG (Santa Cruz-2027) antibodies. DNA was cleaned up using the Qiagen PCR Purification Kit and eluted into $100 \mu \mathrm{l}$ RNase free water. Enrichment analysis was performed by RT-qPCR as described above.

\section{Statistical analysis}

Statistical analyses were performed using GraphPad Prism version 6.0 and statistical significance accepted at $P \leq 0.05$.

\section{Results}

\section{Combining 17-AAG and bicalutamide enhances growth suppression and cell death in AR-sensitive prostate cancer cells}

This study selected doses of 17-AAG and bicalutamide that individually elicit no significant growth inhibitory or cell

Published by Bioscientifica Ltd 
death effects (Fig. 1), as therapeutic doses of Hsp90 inhibitors and AR antagonists are known to induce mechanisms of resistance (Centenera et al. 2012, Maughan $\&$ Antonarakis 2015). Combination of these sub-optimal doses of 17-AAG and bicalutamide significantly inhibited the proliferation and induced death of LNCaP $(P<0.05$; Fig. 1A) and C4-2B ( $P<0.05$; Fig. 1B) prostate cancer cells compared with either vehicle alone or individual agents. LNCaP cell proliferation was reduced by $75 \%$ and cell death induced by 3.2-fold with the most potent combination compared with vehicle treatment. C4-2B cells showed a similar response as LNCaP cells, with proliferation reduced by $81 \%$ and cell death induced by 3.5 -fold compared with vehicle alone. To achieve comparable effects on cell proliferation and death with the agents individually, much higher concentrations of $80 \mathrm{nM}$ 17-AAG or $25 \mu \mathrm{M}$ bicalutamide were required (Supplementary Figure 1, see section on supplementary data given
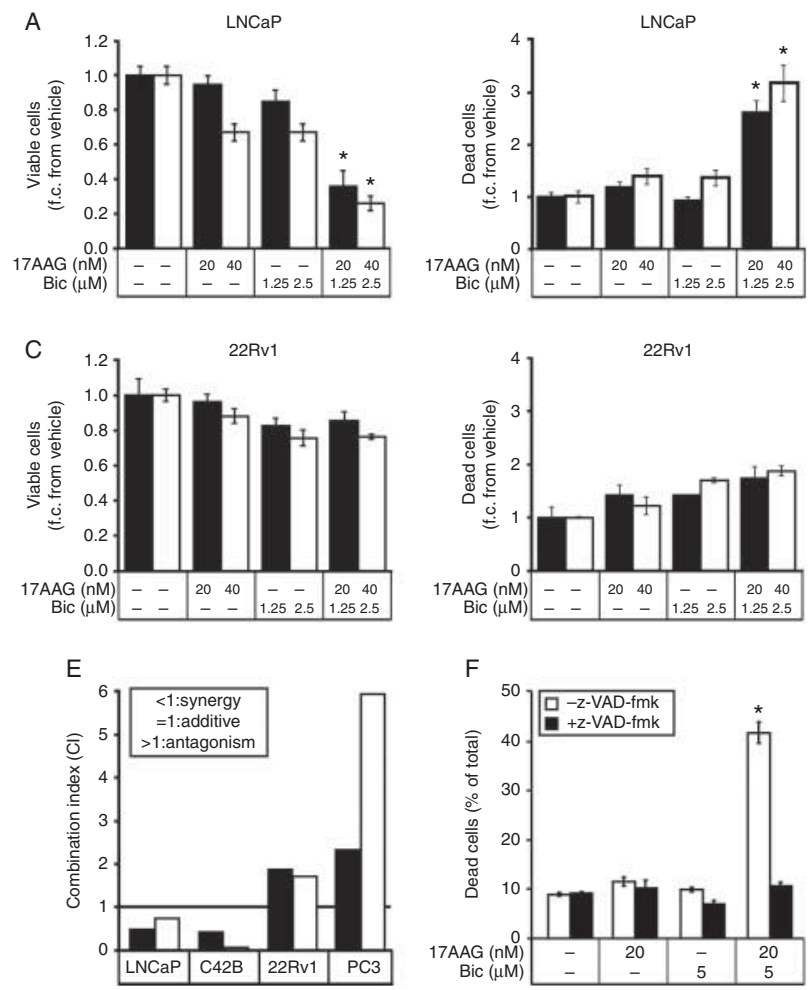

\section{Figure 1}

Combination treatment targeting Hsp90 and AR induces synergistic growth suppression and cell death in AR-sensitive prostate cancer cells. (A) LNCaP, (B) C4-2B, (C) 22Rv1 and (D) PC-3 cells were cultured with 17-AAG or bicalutamide, alone or in combination. Cells were counted after 4 days using a haemocytometer and cell viability assessed by trypan blue dye exclusion. Cell viability (left panels) and cell death (right panels) are presented as a percent of vehicle treatment \pm s.E. of triplicate wells. Results are representative of at least three independent experiments. *ANOVA: $P<0.05$ treatments vs control. (E) Combination indices (Cl) from the above at the end of this article). Combination experiments were replicated in 22Rv1 and $\mathrm{PC}-3$ prostate cancer cell lines that are considered androgen insensitive as they grow in the absence of androgens. No significant changes in 22Rv1 cell proliferation or death were observed compared with vehicle or equivalent doses of the individual agents (Fig. 1C). In PC-3 cells, the higher dose of $40 \mathrm{nM}$ 17-AAG showed some anti-proliferative effect compared with vehicle (Fig. 1D); however, no further reduction in proliferation was observed when cells were co-treated with bicalutamide (Fig. 1D).

\section{7-AAG and bicalutamide act synergistically to induce caspase-dependent cell death}

CIs were calculated using CalcuSyn software, in which synergy is achieved when a combination of drugs is more effective than each agent separately, resulting in a $\mathrm{CI}<1$.
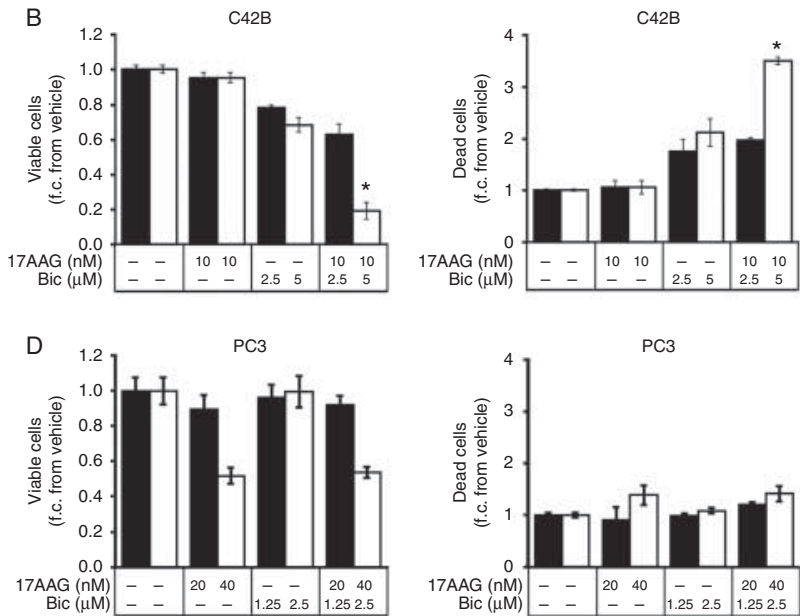

growth curves were calculated according to the method of Chou-Talalay (Chou \& Talalay 1984). The resulting $\mathrm{Cl}$ defines whether the drug combination effect is synergistic $(\mathrm{Cl}<1)$, antagonistic $(\mathrm{Cl}>1)$ or additive $(\mathrm{Cl}=1)$. ( $\mathrm{F}) \mathrm{LNCaP}$ cells were cultured with 17-AAG and bicalutamide, alone or in combination, in the presence or absence of the z-VAD-fmk pancaspase inhibitor. Cells were counted after 4 days as described above. Results are representative of three independent experiments and represent the mean \pm s.E. of triplicate wells. *ANOVA: $P<0.001$ treatments vs control. f.c., fold change.

Published by Bioscientifica Ltd. 
The CI for 17-AAG and bicalutamide in LNCaP and C4-2B were both $<1$, confirming a synergistic interaction between the two agents (Fig. 1E). In 22Rv1 and PC-3 cells, the CI was $>1$ indicating an antagonistic drug interaction (Fig. 1E). Combination-induced cell death was prevented in the presence of the pan-caspase inhibitor z-VAD-fmk, indicative of apoptotic cell death (Fig. 1F).

\section{Global gene expression changes following combination treatment}

To explore the potential mechanisms underlying synergy between 17-AAG and bicalutamide in androgen-dependent cells, gene expression profiling was performed using Affymetrix microarray. Single-agent treatment with 17-AAG or bicalutamide significantly $(P<0.05)$ altered a similar number of transcripts (790 and 609 genes respectively), which increased markedly to 2158 transcripts when the two agents were used in combination (Fig. 2A). Although some overlap with single-agent
17-AAG (14\%) or bicalutamide (16\%) treatment was evident, the majority of genes (59\%) significantly affected by the drug combination were unique. Ingenuity Pathway Analysis (IPA) revealed cell cycle to be the most highly enriched molecular and cellular function by the combination, followed by drug and lipid metabolism (Fig. 2B). Enrichment of these molecular and cellular functions was confirmed using DAVID, in which cell cycle was again the top biological process in combination-treated cells (Supplementary Table 2, see section on supplementary data given at the end of this article). The most highly enriched canonical pathway was protein ubiquitination (Fig. 2C). Several pathways associated with steroid receptor signaling featured in the top 10 canonical pathways, including aldosterone signaling, glucocorticoid receptor signaling, Huntington's disease signaling and, importantly, prostate cancer signaling (Fig. 2C). According to DAVID, prostate cancer signaling was the most significant KEGG pathway in combination-treated cells (Supplementary Table 3).

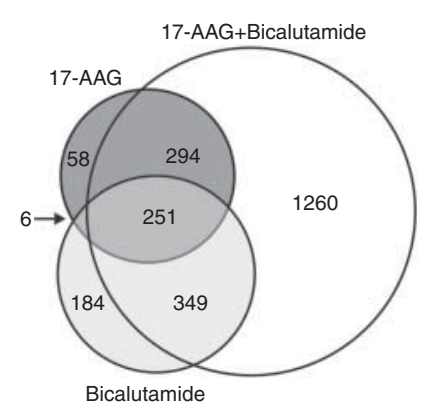

D

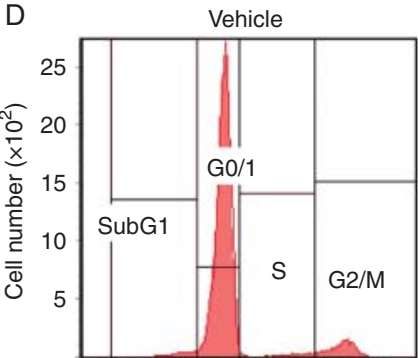

B
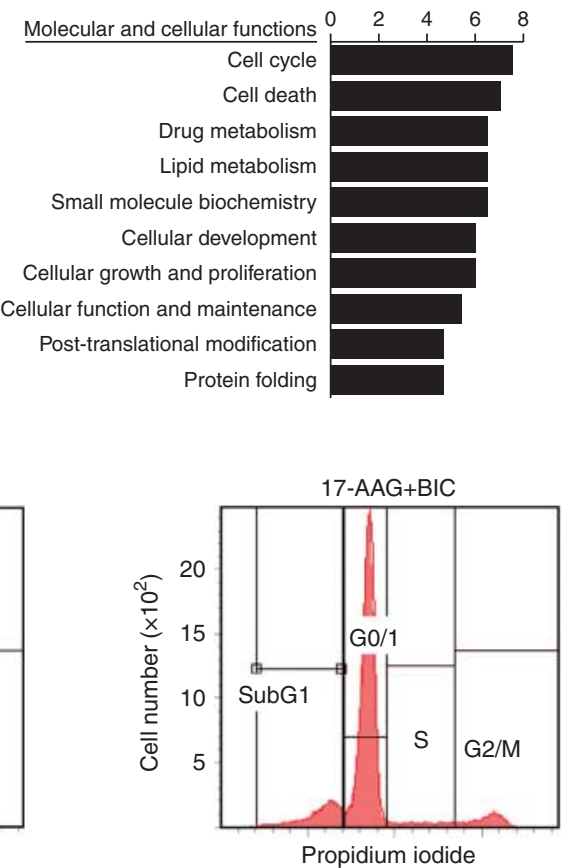
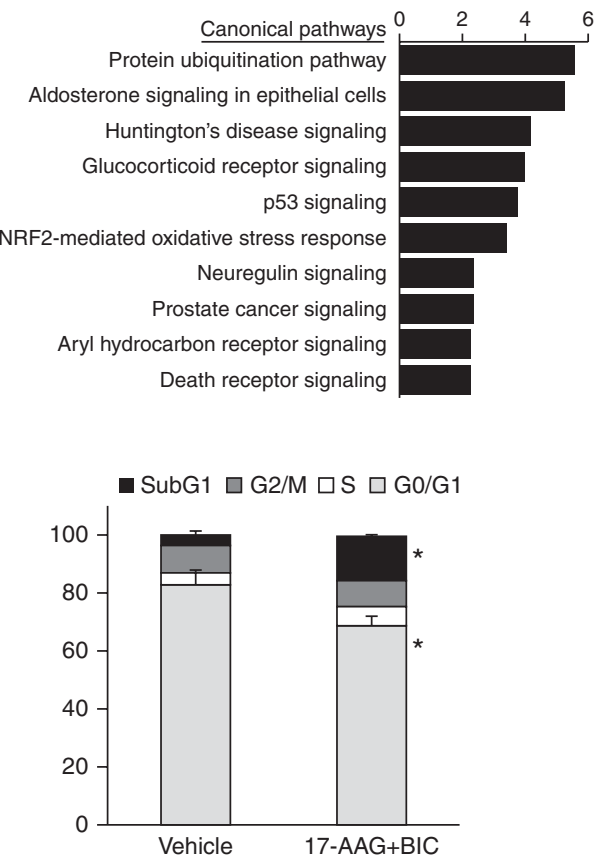

\section{Figure 2}

17-AAG works in synergy with bicalutamide to induce caspase-dependent cell death and amplify global gene expression changes in LNCaP cells. (A) Venn diagram represents the overlap between significantly expressed genes as identified by Affymetrix gene expression profiling in treated LNCaP cells compared with vehicle-treated cells (Benjamini-Hochberg adjusted $P$ values; $P<0.05$ ). (B) Molecular and cellular functions and
(C) canonical pathways enriched by combination treatments as determined by Ingenuity Pathway Analysis. (D) Representative flow cytometry histograms depicting cell cycle distribution in C4-2B cells treated with combined 17-AAG and bicalutamide for $72 \mathrm{~h}$. Bar graph presents the mean \pm s.E. of triplicate wells and is representative of three independent experiments. *ANOVA: $P<0.05$ treatments vs control.

Published by Bioscientifica Ltd 


\section{Combination treatment induces cell cycle inhibition}

Based on the outcomes of the pathway analysis, we investigated how combined 17-AAG and bicalutamide treatment influences the cell cycle. When compared with vehicle treatment, combination-treated cells displayed a significant decrease in G0/G1 phase from $83 \%$ to $63 \%$ $(P<0.05)$, and accumulation of cells in the sub-G1 phase increased from $3 \%$ in controls to $20 \%$ with combined $17-\mathrm{AAG}$ and bicalutamide $(P<0.05$; Fig. $2 \mathrm{D})$. This data not only verifies the pathway analysis but provides further support that the combination treatment induces cell death through apoptosis.

\section{Inhibition of AR signaling is enhanced by co-treatment with 17-AAG and bicalutamide}

The specificity of the combination treatment for ARdependent cells suggests that AR signaling has a mechanistic role in treatment efficacy. This idea was directly interrogated by cross-referencing the list of genes regulated by the combination treatment with the 1755 androgen-regulated genes identified in LNCaP cells by Wang et al. (2009). Approximately 29\% (505/1755) of androgen-responsive genes were significantly $(P<0.05)$ altered by combined 17-AAG and bicalutamide. Cluster analysis revealed that the majority $(87 \% ; 439 / 505)$ of those androgen-regulated genes are antagonized by combination treatment (Fig. 3A). As single agents, 17-AAG and bicalutamide significantly altered the expression of 171 and 300 androgen-regulated genes, respectively, whereas combination treatment markedly increased this number to 505 androgen-regulated genes (Fig. 3A). The Venn diagram in Fig. 3B illustrates that the 505 genes not only were the sum of the individual treatments but also include a set of 207 androgenregulated genes that were novel to combined 17-AAG and bicalutamide. Of the 2158 transcripts significantly altered by combination treatment, only 48 genes displayed $\geq$ twofold change in expression compared with vehicle treatment (Supplementary Table 4, see section on supplementary data given at the end of this article) and, notably, 58\% (28/48) of those were androgen regulated (Fig. 3C). RT-qPCR analysis of two well-known androgenregulated genes, PMEPA1 and NKX3.1, using RNA from the microarray analysis and an independently generated RNA sample set validated these findings (Fig. 3D). Expression of AR was not altered by the low doses of 17-AAG or bicalutamide, either alone or in combination (Fig. 3E). Collectively, these findings suggest that using 17-AAG and bicalutamide in a combinatorial strategy broadens the$$
\text { A }
$$
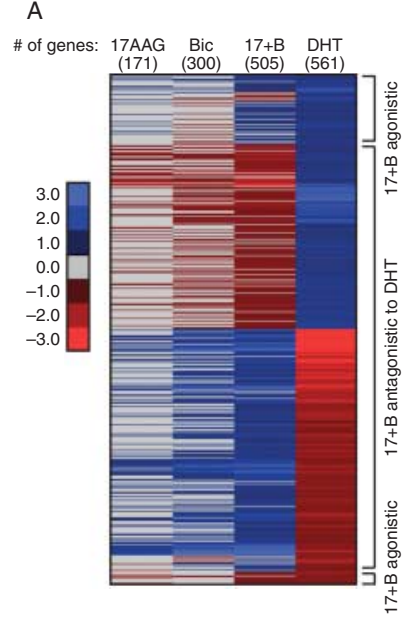

B

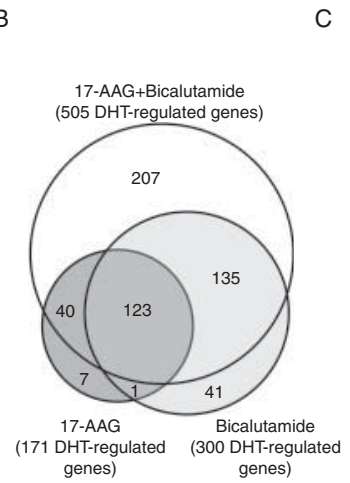

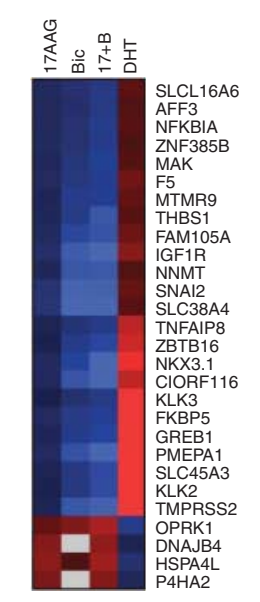

D

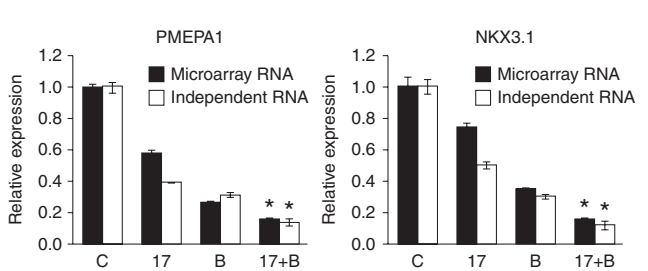

$E$

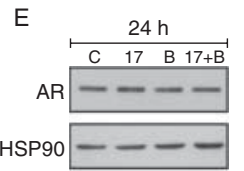

\section{Figure 3}

Combining 17-AAG with bicalutamide enhances inhibition of AR signaling. (A) Heat map represents androgen-regulated genes that were significantly $(P<0.05)$ up-regulated (blue) or down-regulated (red) by the indicated treatments. Hierarchical clustering was performed by applying the complete linkage rule in Cluster3.0 and heat maps constructed using Java TreeView (http://rana.Ibl.gov/eisensoftware.htm). (B) Venn diagram represents the overlap between androgen-regulated genes significantly altered by 17-AAG or bicalutamide, alone or in combination (BenjaminiHochberg adjusted $P$ values; $P<0.05$ ). (C) Heat map represents the subset of androgen-regulated genes that were up-regulated (blue) or downregulated (red) by at least twofold by the indicated treatments. (D) Enhanced expression of a subset of androgen-regulated genes in combination-treated LNCaP cells was validated by qPCR analysis of PMEPA1 and NKX3.1. Gene expression was normalized to GUSB and $L 19$ and represents the mean \pm s.E. of three biological replicates. *ANOVA: $P<0.05$ treatment vs control. (E) LNCaP cells treated for $24 \mathrm{~h}$ with the indicated doses of 17-AAG and bicalutamide, alone or in combination, were analyzed by western blot for modulation of AR. HSP90 was used as a loading control.

Published by Bioscientifica Ltd 
blockade of AR signaling over a larger number of AR-regulated target genes.

\section{Co-treatment with 17-AAG and bicalutamide prevents chromatin binding and nuclear localization of AR}

Combining 17-AAG and bicalutamide markedly decreased the binding of AR to regulatory regions of the KLK3, FKBP5 and C1ORF116 genes (Fig. 4A), consistent with a loss of AR chromatin occupancy underlying the observed silencing of AR-regulated genes. To evaluate whether AR nuclear translocation was also impaired, we assessed the effect of the combination on subcellular localization of an enhanced green fluorescent protein (EGFP)-tagged AR. AR was predominantly localized to the nucleus in vehicletreated PC-3 cells expressing EGFP-AR cultured in full serum, similar to that observed in cells cultured in androgen-deplete (charcoal-stripped) serum containing
A

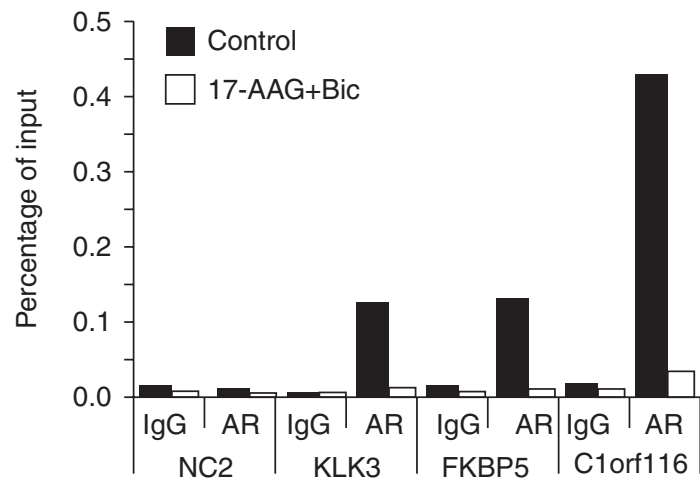

C

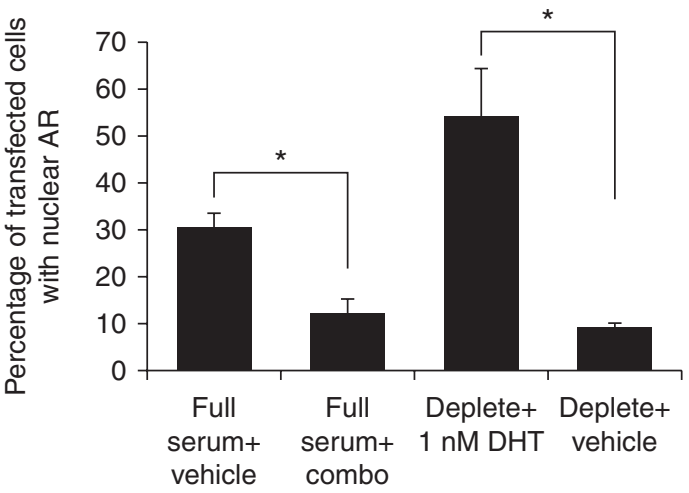

B

Full serum+ vehicle
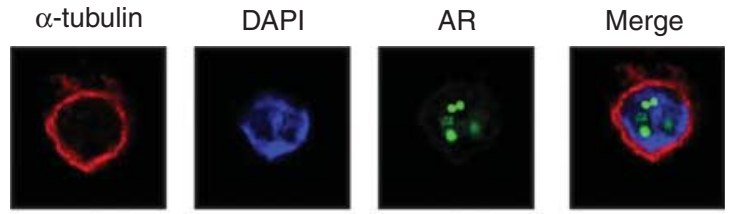

Full serum+
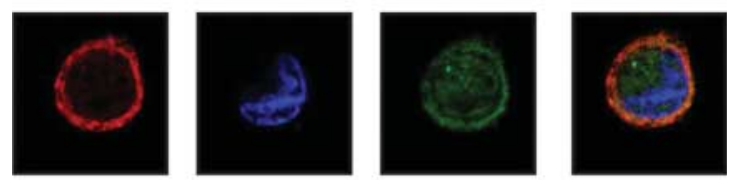

Deplete serum+ $1 \mathrm{nM}$ DHT
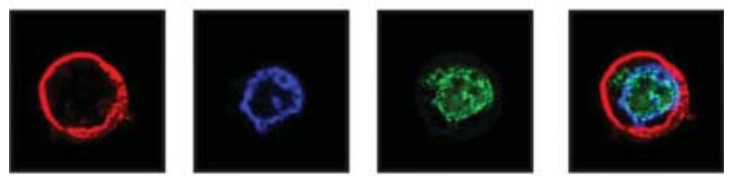

Deplete serum+ vehicle
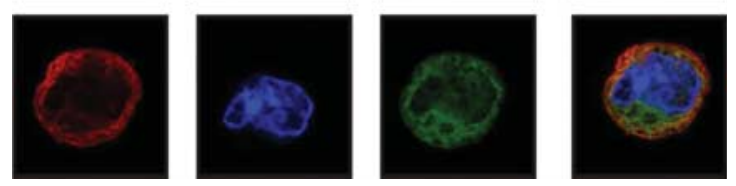

D

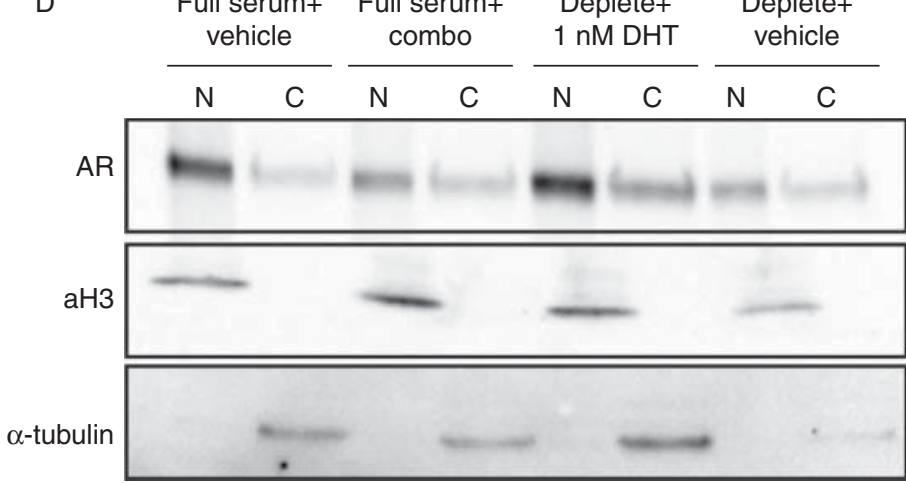

\section{Figure 4}

Combined 17-AAG with bicalutamide inhibits AR nuclear translocation and prevents DNA binding. (A) Recruitment of AR to the promoter of AR-regulated genes $K L K 3, F K B P 5, C 1 O R F 116$ was prevented by treatment with combined 17-AAG and bicalutamide. Values are presented as percentage input. Input values were obtained from samples treated in the same way as the experimental ones, except that no immunoprecipitation steps were performed. NC2 is an irrelevant region of the PSA gene. (B) Confocal microscopy of representative PC-3 cells transfected with pEGFP-AR and treated for $4 \mathrm{~h}$ with vehicle or combined 17-AAG and bicalutamide in medium containing full serum (upper two panels) or vehicle or $1 \mathrm{nM}$ DHT in medium containing steroid-deplete serum (lower two panels). The nucleus and cytoplasm were stained with DAPI and $\alpha$-tubulin respectively. (C) Evaluation of fluorescent localization images represented as the percent of transfected PC-3 cells with nuclear AR as determined by ImageJ analysis. *Unpaired $t$ test: $P<0.05$ treatment vs vehicle. (D) LNCaP cell fractionation demonstrating the location of AR following the indicated treatments. $\alpha$-tubulin was used as a cytoplasmic marker; acetylated $\mathrm{H} 3$ was used as nuclear marker.

Published by Bioscientifica Ltd 
$1 \mathrm{nM}$ DHT (Fig. 4B and C). In contrast, combination treatment blocked the nuclear import of AR, which remained in a diffuse pattern, similar to cells that had been grown in androgen-deplete serum for 3 days (Fig. 4B and $\mathrm{C}$ ). As combination treatment does not significantly alter AR steady-state levels (Fig. 3E), the decrease in nuclear AR cannot be attributed to altered stability or turnover. Subcellular fractionation of LNCaP cells verified a decrease in nuclear AR with combined 17-AAG and bicalutamide treatment (Fig. 4C).

\section{Combinatorial synergy is retained by new generation inhibitors AUY922 and enzalutamide}

We extended our studies to investigate whether newer generation agents AUY922 and enzalutamide would also exhibit synergy when used in combination. AUY922 is a synthetic Hsp90 inhibitor with much greater potency than 17-AAG but also improved solubility and reduced toxicity (Eccles et al. 2008, Centenera et al. 2012). When treated in combination with bicalutamide, highly similar patterns of cell growth inhibition ( $80 \%$ vs vehicle) and death (4.4-fold vs vehicle) were achieved using AUY922 in place of 17-AAG $(P<0.05$; Fig. $5 \mathrm{~A})$. We then alternated the agents and investigated whether the second generation AR antagonist enzalutamide is capable of synergy as part of a combinatorial treatment. Enzalutamide is
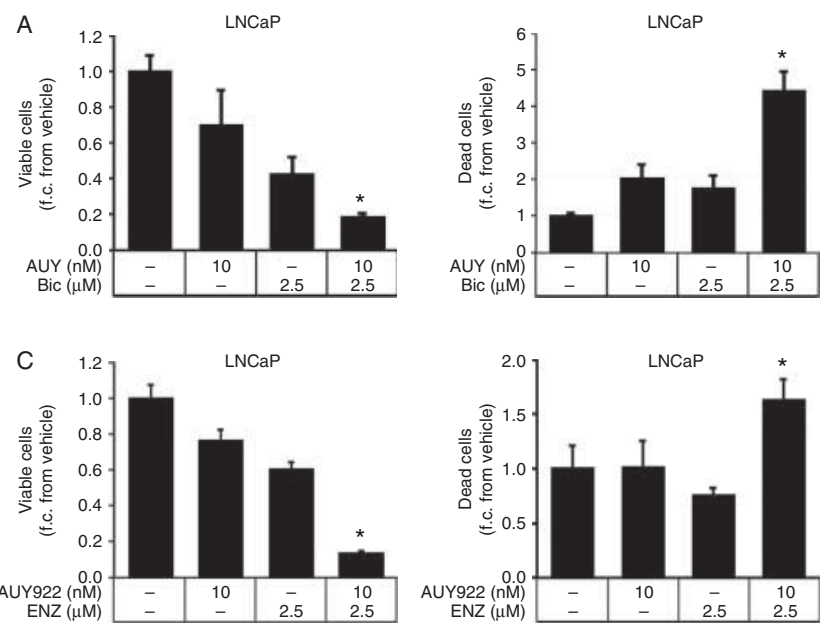

Figure 5

Combinatorial synergy is retained with new generation Hsp90 inhibitor AUY922 and AR antagonist enzalutamide. LNCaP cells were treated with (A) AUY922 and bicalutamide, (B) 17-AAG and enzalutamide or (C) AUY922 and enzalutamide, alone or in combination. (D) 22RV1 cells were treated with AUY922 and enzalutamide, alone or in combination. Cells were counted after 4 days using a haemocytometer and cell viability assessed by trypan blue dye exclusion. Cell viability (left panel) and cell death superior to bicalutamide in terms of binding affinity and disruption of AR localization and DNA binding and is clinically approved for use in CRPC (Tran et al. 2009, Scher et al. 2010). Significant cell growth inhibition and death of LNCaP cells was observed when enzalutamide was used in combination with either 17-AAG $(P<0.05$; Fig. 6B) or AUY922 $(P<0.05$; Fig. 6C).

\section{Co-treatment with AUY922 and enzalutamide inhibits growth of androgen-insensitive 22Rv1 cells and prevents induction of AR-V7}

Previously we have demonstrated that AR-V7 expressing prostate cancer cells are sensitive to AUY922 (Gillis et al. 2013). Given the efficacy of co-treatment with AUY922 and enzalutamide we observed in LNCaP cells, we evaluated the combination of these two agents in AR-V7 expressing 22Rv1 cells and found that cell growth inhibition was reduced significantly by $40 \%$ compared to vehicle treatment $(P<0.05$; Fig. 5D). In addition, we demonstrated that expression of AR-V7 is not induced with combined AUY922 and enzalutamide treatment (Fig. 5E), whereas therapeutic doses of both enzalutamide (Supplementary Figure 2, see section on supplementary data given at the end of this article) (Li et al. 2013) and AUY922 (Gillis et al. 2013) do acutely induce AR-V expression.
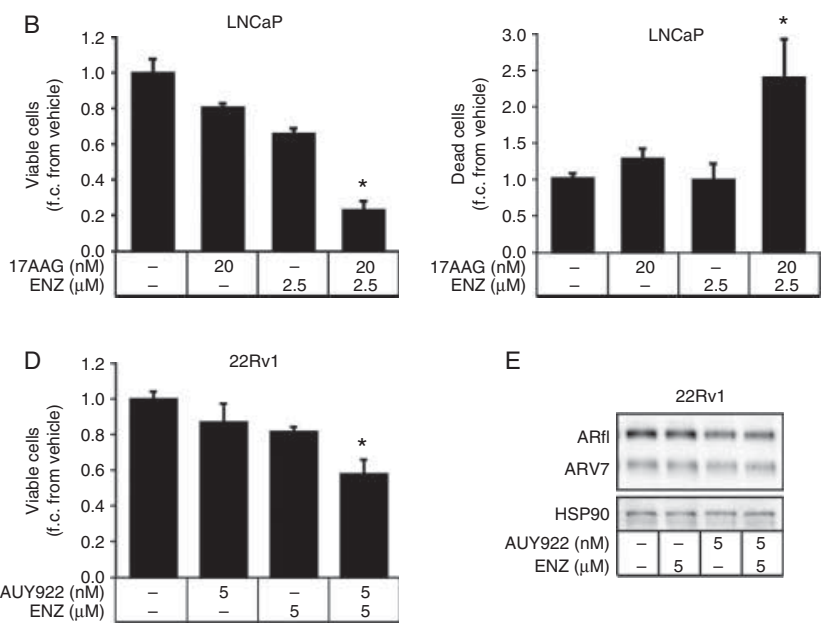

E

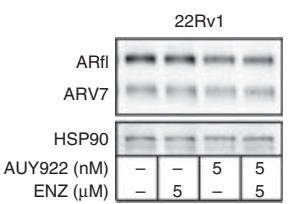

(right panel) are presented as fold change from vehicle treatment \pm s.E. of triplicate wells. Results are representative of at least three independent experiments. *ANOVA: $P<0.05$ treatments vs control. (E) 22RV1 cells treated with the indicated doses of AUY922 and enzalutamide, alone or in combination, were analyzed by western blot for modulation of ARfI and ARV7. HSP90 was used as a loading control. f.c., fold change.

Published by Bioscientifica Ltd 


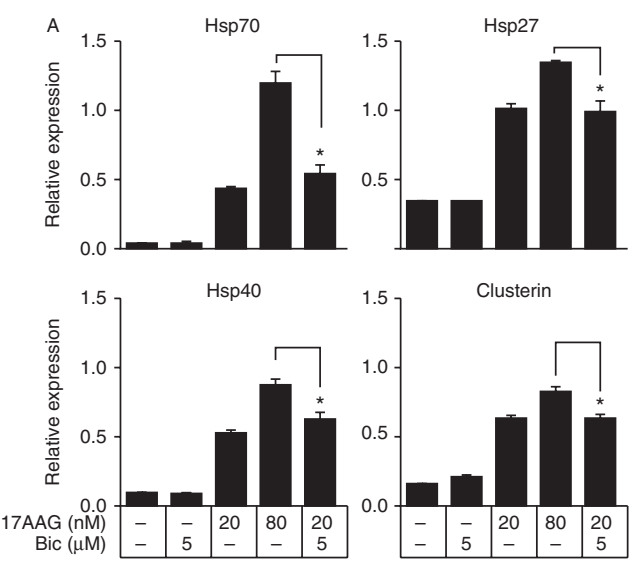

B
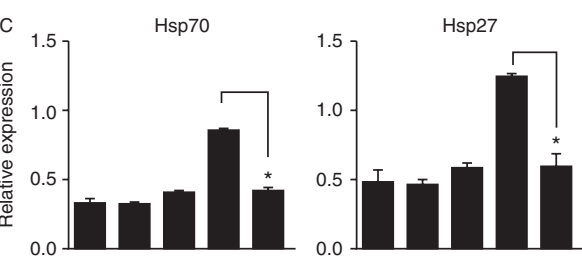

\begin{tabular}{rl|c|c|c|c|} 
17AAG $(\mathrm{nM})$ & - & - & 20 & 80 & 20 \\
Bic $(\mu \mathrm{M})$ & - & 5 & - & - & 5 \\
\hline
\end{tabular}
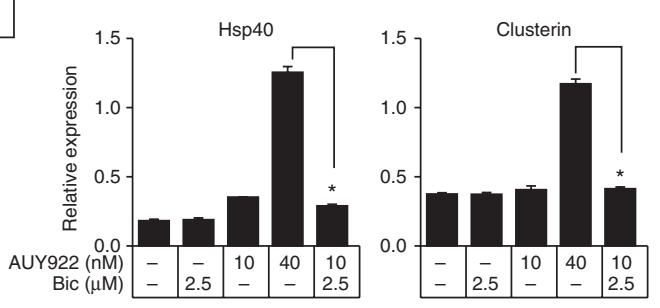

Figure 6

Combination treatment minimizes mechanisms of resistance to $\mathrm{Hsp90}$ inhibitors and AR antagonists. LNCaP cells were treated with low dose 17-AAG $(20 \mathrm{nM})$ and bicalutamide $(5 \mu \mathrm{M})$, alone or in combination, or with a therapeutic dose of 17-AAG ( $80 \mathrm{nM})$. (A) Total RNA was extracted after $6 \mathrm{~h}$ and expression of genes encoding heat shock proteins Hsp70, Hsp40, Hsp27 and CLU were evaluated by RT-qPCR. Expression was normalized to L19 and GUSB. Error bars represent mean \pm s.E. of three biological

\section{Co-treatment with 17-AAG and bicalutamide minimizes the heat shock response}

The most significantly up-regulated transcripts in combination-treated LNCaP cells were those that encode members of the heat shock protein family, including HSPA1A, HSPA1B, DNAJB1, and CLU (Supplementary Table 4). Of the 13 genes that were up-regulated by $\geq$ twofold compared with vehicle-treated cells, $77 \%(10 / 13)$ encode heat shock proteins (Supplementary Table 4). The transcriptional induction of heat shock proteins in response to cellular stress, known as the heat shock response, serves to repair damaged proteins or prepare them for proteasomal degradation (Zou et al. 1998). The observed up-regulation of heat shock proteins is therefore consistent with protein ubiquitination being the most significantly enriched canonical pathway in combinationtreated cells (Fig. 2D). Increased expression of genes encoding heat shock proteins HSP70 (HSPA1A/B), HSP40 (DNAJB1), HSP27 (HSPB1) and CLU (CLU) with combined 17-AAG and bicalutamide treatment was compared with vehicle or the equivalent dose of bicalutamide alone, but there was no significant difference to the equivalent dose of 17-AAG alone ( $P<0.05$; Fig. $5 \mathrm{~A})$. Moreover, induction of heat shock proteins in LNCaP cells co-treated with 17-AAG and bicalutamide was significantly lower than in cells treated with therapeutic doses $(80 \mathrm{nM})$ of $17-\mathrm{AAG}$ alone $(P<0.05$, Fig. $5 \mathrm{~A})$, despite the fact that both treatments induced equivalent cell growth suppression and death replicates. *ANOVA: $P<0.05$ combination vs $80 \mathrm{nM}$ 17-AAG. (B) Whole cell lysates were analyzed by western blotting with $A R N-20$. Densitometry was used to quantitate AR steady state levels relative to HSP90 loading control. Values are presented as fold change over vehicle treatment. (C) LNCaP cells were treated with low doses of AUY922 $(10 \mathrm{nM})$ and bicalutamide $(2.5 \mu \mathrm{M})$, alone or in combination. Total RNA was extracted and RT-qPCR performed as in panel A. *ANOVA: $P<0.05$ combination vs $40 \mathrm{nM}$ AUY922.

(Fig. 1A and Supplementary Figure 1). Concomitant changes in the protein levels of HSP70 and HSP27 were observed (Fig. 5B). Combining AUY922 with bicalutamide also minimized induction of the heat shock response when compared with a lethal dose $(40 \mathrm{nM})$ of AUY922 alone $(P<0.05$; Fig. 5D).

\section{Discussion}

With recent compelling evidence that CRPC arises as an adaptive response to maintain AR signaling despite castrate levels of circulating testosterone, we propose that combinatorial targeting of the AR using drugs with different mechanisms of action may provide a more effective strategy to control CRPC and its associated mortality (Chen et al. 2008). This study demonstrates that Hsp90 inhibitors act in synergy with AR antagonists to enhance AR blockade and reduce survival of prostate cancer cells while also minimizing known mechanisms of resistance. Importantly, these effects were demonstrated using doses of each agent that individually were not effective and are both clinically achievable and tolerable (Kelly et al. 2003, Tyrrell et al. 2006, Solit et al. 2007).

Using four different prostate cancer cell lines, we found that combining 17-AAG and bicalutamide is effective in cells that are sensitive to androgens (LNCaP, C4-2B) but is not effective in cells that are weakly activated by androgens and express constitutively activated AR

Published by Bioscientifica Ltd 
spliced variants (22Rv1) or are androgen independent and AR negative (PC-3). These findings focused our investigation into androgen signaling as a key mechanism of action underpinning the efficacy of the combination treatment. Minimal changes in AR transcript or protein levels were observed in combination-sensitive cells. This was unexpected, in light of previous reports of enhanced interaction between bicalutamide-bound AR and Hsp90 and the fact that Hsp90 inhibitors are well documented to induce proteasomal degradation of the AR (Centenera et al. 2013), but likely reflects the low doses that were used in this study. ChIP and localization analysis revealed instead that the AR is held in the cytoplasm by combined 17-AAG and bicalutamide, thereby preventing nuclear translocation and loss of AR occupancy at AR-regulatory regions in chromatin. These results echo previous biochemical studies that observed cytoplasmic aggregates in cells treated with bicalutamide and geldanamycin, the predecessor of 17-AAG (Georget et al. 2002). Reduced AR nuclear transport and impaired chromatin binding explains the pronounced antagonistic effects of the combination treatment on androgen signaling. This mechanism of action is similar to that observed for the latest generation AR antagonist enzalutamide (Tran et al. 2009) and provides a major advantage for combination treatment over bicalutamide as a single agent. Bicalutamide does not prevent AR from translocating to the nucleus or binding DNA but rather stimulates the assembly of an inactive receptor complex at AR binding sites (Masiello et al. 2002). Increased expression of $\mathrm{AR}$ or coactivator proteins can reduce the efficacy of bicalutamide and even cause a shift in action from antagonist to agonist. Use of bicalutamide in a combinatorial strategy with Hsp90 inhibition therefore provides an opportunity to markedly enhance its activity, even in the context of aberrant AR signaling that is characteristic of CRPC (Robinson et al. 2015).

Inhibition of androgen signaling as the primary mechanism of action of 17-AAG and bicalutamide is consistent with the associated molecular and cellular functions of cell cycle, cell death and lipid metabolism that were identified through genome-wide profiling. Cross-talk between AR and the cell cycle is well known to influence the mitogenic response to androgens (Schiewer et al. 2012). Androgen-sensitive cells that are deprived of androgen exit the cell cycle and arrest in G0 (Knudsen et al. 1998, Agus et al. 1999), much like the cell cycle effects of combined 17-AAG and bicalutamide treatment observed here. Finally, lipid metabolism is highly regulated by androgens in prostate cancer cells
(Swinnen et al. 2004). Bicalutamide inhibits lipid synthesis in LNCaP cells (Swinnen et al. 1996), and increased levels of key lipogenic enzymes have been reported in CRPC patients (Rossi et al. 2003, Ettinger et al. 2004).

Although AR-V7 expressing 22Rv1 cells (Dehm et al. 2008, Guo et al. 2009) were refractory to combined 17-AAG and bicalutamide, they were highly sensitive to a combination of the new generation agents AUY922 and enzalutamide. This is a critical finding as ARV expression represents a potential mechanism of resistance to ADT in prostate cancer cells, driving the progression to CRPC (Nadiminty et al. 2013). In particular, detection of AR-V7 in circulating tumor cells has been associated with resistance to enzalutamide (Antonarakis et al. 2014), which is consistent with the resistance of $22 \mathrm{Rv} 1$ cells to this AR antagonist. Here we demonstrate that, unlike therapeutic doses of enzalutamide (Hu et al. 2012, Li et al. 2013) or AUY922 (Gillis et al. 2013, He et al. 2013, Shafi et al. 2013) that increase AR-V7 expression in cell lines, xenografts and ex vivo cultured prostate tumors, treating 22Rv1 cells with low dose combined AUY922 and enzalutamide prevents induction of AR-V7 expression.

The heat shock response is an ancient physiological reaction to cellular stress, at times when protein aggregation and denaturation is prevalent such as heat, hypoxia and toxicity, and is characterized by induction of stress response proteins Hsp70, Hsp27 and Clusterin (Whitesell et al. 2003). This cytoprotective response has been posited as a mechanism of resistance to Hsp90 inhibitors and an underlying reason for the failure of 17-AAG as a single agent therapy (Bagatell et al. 2000). Our results demonstrate that the heat shock response to combined 17-AAG and bicalutamide is significantly reduced compared with single agent doses of 17-AAG or AUY922 that have equivalent anti-proliferative effects. This reveals a key mechanistic advantage for the combination, compared to single-agent treatment with N-terminal Hsp90 inhibitors, that may markedly improve patient responses. Similar to combined 17-AAG and bicalutamide, C-terminal targeted Hsp90 inhibitors do not elicit a heat shock response (Conde et al. 2009, Eskew et al. 2011), and development of these agents is currently being pursued to take advantage of this characteristic.

The AR antagonists bicalutamide and enzalutamide are established prostate cancer therapies that target $\mathrm{AR}$ ligand binding, but resistance to these agents is inevitable. This study demonstrates that both current and emerging clinical Hsp90 inhibitors work in synergy with bicalutamide or enzalutamide to markedly enhance growth suppression and death of prostate cancer cells.

Published by Bioscientifica Ltd. 
Two major advantages of this combination treatment are noteworthy for their clinical implications. First, antiproliferative and pro-apoptotic effects were observed using up to fourfold less Hsp90 inhibitor and up to tenfold less AR antagonist than the respective single agent treatments. Secondly, the capacity to use reduced doses of Hsp90 inhibitor or AR antagonist minimizes the potential for resistance through induction of the heat shock response or through increased ARV expression. Collectively, these results provide a strong rationale for evaluation of Hsp90 inhibitors in combination with AR antagonists for treatment of advanced prostate cancer.

\section{Supplementary data}

This is linked to the online version of the paper at http://dx.doi.org/10.1530/ ERC-14-0541.

\section{Declaration of interest}

The authors declare that there is no conflict of interest that could be perceived as prejudicing the impartiality of the research reported.

\section{Funding}

This work was supported by the National Health and Medical Research Council of Australia (grant number 453662), Cancer Australia (grant number 627229). D L Marrocco-Tallarigo was the recipient of a University of Adelaide Postgraduate Award. S L Carter was the recipient of a Lion's Medical Research Foundation Postgraduate Scholarship. M M Centenera is a Prostate Cancer Foundation of Australia Young Investigator. L M Butler was supported by senior research fellowships from the Cancer Council South Australia and the Australian Research Council.

\section{Author contribution statement}

M M Centenera, D L Marrocco-Tallarigo and L M Butler were involved in the concept and design of the project. M M Centenera, S L Carter, D L MarroccoTallarigo, J L Gillis and R H Grose performed experiments and analyzed data. M M Centenera and L M Butler wrote the manuscript. All authors provided critical input throughout the project and revised the manuscript.

\section{Acknowledgements}

The authors thank Dr Mark Van Der Hoek at the Adelaide Microarray Facility, Dr Luke Selth for assistance with microarray data analysis, Ms Heather Armstrong for assistance with immunofluorescent staining and imaging and Dr Makoto Kamei at the Confocal Microscopy Facility at SAHMRI.

\section{References}

Agus DB, Cordon-Cardo C, Fox W, Drobnjak M, Koff A, Golde DW \& Scher HI 1999 Prostate cancer cell cycle regulators: response to androgen withdrawal and development of androgen independence.
Journal of the National Cancer Institute 91 1869-1876. (doi:10.1093/ jnci/91.21.1869)

Antonarakis ES, Lu C, Wang H, Luber B, Nakazawa M, Roeser JC, Chen Y, Mohammad TA, Chen Y, Fedor HL et al. 2014 AR-V7 and resistance to enzalutamide and abiraterone in prostate cancer. New England Journal of Medicine 371 1028-1038. (doi:10.1056/NEJMoa1315815)

Bagatell R, Paine-Murrieta GD, Taylor CW, Pulcini EJ, Akinaga S, Benjamin IJ \& Whitesell L 2000 Induction of a heat shock factor 1-dependent stress response alters the cytotoxic activity of hsp90-binding agents. Clinical Cancer Research 6 3312-3318.

Banerji U, O’Donnell A, Scurr M, Pacey S, Stapleton S, Asad Y, Simmons L, Maloney A, Raynaud F, Campbell M et al. 2005 Phase I pharmacokinetic and pharmacodynamic study of 17-allylamino, 17-demethoxygeldanamycin in patients with advanced malignancies. Journal of Clinical Oncology 23 4152-4161. (doi:10.1200/JCO.2005.00.612)

Benjamini Y \& Hochberg Y 1995 Controlling the false discovery rate: a practical and powerful approach to multiple testing. Journal of the Royal Statistical Society. Series B (Methodological) 57 289-300.

Buchanan G, Greenberg NM, Scher HI, Harris JM, Marshall VR \& Tilley WD 2001 Collocation of androgen receptor gene mutations in prostate cancer. Clinical Cancer Research 7 1273-1281.

Cai C \& Balk SP 2011 Intratumoral androgen biosynthesis in prostate cancer pathogenesis and response to therapy. Endocrine-Related Cancer 18 R175-R182. (doi:10.1530/ERC-10-0339)

Centenera MM, Gillis JL, Hanson A, Jindal S, Taylor RA, Risbridger G, Sutherland PD, Scher HI, Raj GV, Knudsen KE et al. 2012 Evidence for efficacy of new Hsp90 inhibitors revealed by ex vivo culture of human prostate tumors. Clinical Cancer Research 18 3562-3570. (doi:10.1158/ 1078-0432.CCR-12-0782)

Centenera MM, Fitzpatrick AK, Tilley WD \& Butler LM 2013 Hsp90: still a viable target in prostate cancer. Biochimica et Biophysica Acta 1835 211-218.

Chen CD, Welsbie DS, Tran C, Baek SH, Chen R, Vessella R, Rosenfeld MG \& Sawyers CL 2004 Molecular determinants of resistance to antiandrogen therapy. Nature Medicine 10 33-39. (doi:10.1038/nm972)

Chen Y, Sawyers CL \& Scher HI 2008 Targeting the androgen receptor pathway in prostate cancer. Current Opinion in Pharmacology 8 440-448. (doi:10.1016/j.coph.2008.07.005)

Chou TC \& Talalay P 1984 Quantitative analysis of dose-effect relationships: the combined effects of multiple drugs or enzyme inhibitors. Advances in Enzyme Regulation 22 27-55.

Conde R, Belak ZR, Nair M, O'Carroll RF \& Ovsenek N 2009 Modulation of Hsf1 activity by novobiocin and geldanamycin. Biochemistry and Cell Biology 87 845-851. (doi:10.1139/O09-049)

Dehm SM, Schmidt LJ, Heemers HV, Vessella RL \& Tindall DJ 2008 Splicing of a novel androgen receptor exon generates a constitutively active androgen receptor that mediates prostate cancer therapy resistance. Cancer Research 68 5469-5477. (doi:10.1158/0008-5472.CAN-08-0594)

Eccles SA, Massey A, Raynaud FI, Sharp SY, Box G, Valenti M, Patterson L, de Haven Brandon A, Gowan S, Boxall F et al. 2008 NVP-AUY922: a novel heat shock protein 90 inhibitor active against xenograft tumor growth, angiogenesis, and metastasis. Cancer Research 68 2850-2860. (doi:10.1158/0008-5472.CAN-07-5256)

Eisen MB, Spellman PT, Brown PO \& Botstein D 1998 Cluster analysis and display of genome-wide expression patterns. PNAS 95 14863-14868. (doi:10.1073/pnas.95.25.14863)

Enmon R, Yang WH, Ballangrud AM, Solit DB, Heller G, Rosen N, Scher HI \& Sgouros G 2003 Combination treatment with 17-N-allylamino17-demethoxy geldanamycin and acute irradiation produces supraadditive growth suppression in human prostate carcinoma spheroids. Cancer Research 63 8393-8399.

Eskew JD, Sadikot T, Morales P, Duren A, Dunwiddie I, Swink M, Zhang X, Hembruff S, Donnelly A, Rajewski RA et al. 2011 Development and characterization of a novel C-terminal inhibitor of Hsp90 in androgen dependent and independent prostate cancer cells. BMC Cancer 11468. (doi:10.1186/1471-2407-11-468) 
Ettinger SL, Sobel R, Whitmore TG, Akbari M, Bradley DR, Gleave ME \& Nelson CC 2004 Dysregulation of sterol response element-binding proteins and downstream effectors in prostate cancer during progression to androgen independence. Cancer Research 64 2212-2221. (doi:10.1158/0008-5472.CAN-2148-2)

Gandhi N, Wild AT, Chettiar ST, Aziz K, Kato Y, Gajula RP, Williams RD, Cades JA, Annadanam A, Song D et al. 2013 Novel Hsp90 inhibitor NVP-AUY922 radiosensitizes prostate cancer cells. Cancer Biology \& Therapy 14 347-356. (doi:10.4161/cbt.23626)

Georget V, Terouanne B, Nicolas JC \& Sultan C 2002 Mechanism of antiandrogen action: key role of hsp90 in conformational change and transcriptional activity of the androgen receptor. Biochemistry $\mathbf{4 1}$ 11824-11831. (doi:10.1021/bi0259150)

Gillis JL, Selth LA, Centenera MM, Townley SL, Sun S, Plymate SR, Tilley WD \& Butler LM 2013 Constitutively-active androgen receptor variants function independently of the HSP90 chaperone but do not confer resistance to HSP90 inhibitors. Oncotarget 4 691-704.

Guo Z, Yang X, Sun F, Jiang R, Linn DE, Chen H, Chen H, Kong X, Melamed J, Tepper CG et al. 2009 A novel androgen receptor splice variant is up-regulated during prostate cancer progression and promotes androgen depletion-resistant growth. Cancer Research 69 2305-2313. (doi:10.1158/0008-5472.CAN-08-3795)

He S, Zhang C, Shafi AA, Sequeira M, Acquaviva J, Friedland JC, Sang J, Smith DL, Weigel NL, Wada Y et al. 2013 Potent activity of the Hsp90 inhibitor ganetespib in prostate cancer cells irrespective of androgen receptor status or variant receptor expression. International Journal of Oncology 42 35-43.

Heath EI, Hillman DW, Vaishampayan U, Sheng S, Sarkar F, Harper F, Gaskins M, Pitot HC, Tan W, Ivy SP et al. 2008 A phase II trial of 17-allylamino-17-demethoxygeldanamycin in patients with hormonerefractory metastatic prostate cancer. Clinical Cancer Research 14 7940-7946. (doi:10.1158/1078-0432.CCR-08-0221)

Hu R, Lu C, Mostaghel EA, Yegnasubramanian S, Gurel M, Tannahill C, Edwards J, Isaacs WB, Nelson PS, Bluemn E et al. 2012 Distinct transcriptional programs mediated by the ligand-dependent full-length androgen receptor and its splice variants in castration-resistant prostate cancer. Cancer Research 72 3457-3462. (doi:10.1158/00085472.CAN-11-3892)

Huang da W, Sherman BT \& Lempicki RA 2009 Systematic and integrative analysis of large gene lists using DAVID bioinformatics resources. Nature Protocols 4 44-57. (doi:10.1038/nprot.2008.211)

Iyer G, Morris MJ, Rathkopf D, Slovin SF, Steers M, Larson SM, Schwartz LH, Curley T, DeLaCruz A, Ye Q et al. 2012 A phase I trial of docetaxel and pulse-dose 17-allylamino-17-demethoxygeldanamycin in adult patients with solid tumors. Cancer Chemotherapy and Pharmacology 69 1089-1097. (doi:10.1007/s00280-011-1789-3)

Izar B, Rotow J, Gainor J, Clark J \& Chabner B 2013 Pharmacokinetics, clinical indications, and resistance mechanisms in molecular targeted therapies in cancer. Pharmacological Reviews 65 1351-1395. (doi:10.1124/pr.113.007807)

Karantanos T, Corn PG \& Thompson TC 2013 Prostate cancer progression after androgen deprivation therapy: mechanisms of castrate resistance and novel therapeutic approaches. Oncogene 32 5501-5511. (doi:10.1038/onc.2013.206)

Kelly WK, Richon VM, O'Connor O, Curley T, MacGregor-Curtelli B, Tong W, Klang M, Schwartz L, Richardson S, Rosa E et al. 2003 Phase I clinical trial of histone deacetylase inhibitor: suberoylanilide hydroxamic acid administered intravenously. Clinical Cancer Research 9 3578-3588.

Knudsen KE, Arden KC \& Cavenee WK 1998 Multiple G1 regulatory elements control the androgen-dependent proliferation of prostatic carcinoma cells. Journal of Biological Chemistry $27320213-20222$. (doi:10.1074/jbc.273.32.20213)

Ku S, Lasorsa E, Adelaiye R, Ramakrishnan S, Ellis L \& Pili R 2014 Inhibition of Hsp90 augments docetaxel therapy in castrate resistant prostate cancer. PLOS ONE 9 e103680. (doi:10.1371/journal.pone.0103680)
Kuil CW, Berrevoets CA \& Mulder E 1995 Ligand-induced conformational alterations of the androgen receptor analyzed by limited trypsinization. Studies on the mechanism of antiandrogen action. Journal of Biological Chemistry 270 27569-27576. (doi:10.1074/jbc.270.46.27569)

Labrie F 2011 Blockade of testicular and adrenal androgens in prostate cancer treatment. Nature Reviews. Urology 8 73-85. (doi:10.1038/nrurol. 2010.231)

Li Y, Alsagabi M, Fan D, Bova GS, Tewfik AH \& Dehm SM 2011 Intragenic rearrangement and altered RNA splicing of the androgen receptor in a cell-based model of prostate cancer progression. Cancer Research $\mathbf{7 1}$ 2108-2117. (doi:10.1158/0008-5472.CAN-10-1998)

Li Y, Chan SC, Brand LJ, Hwang TH, Silverstein KA \& Dehm SM 2013 Androgen receptor splice variants mediate enzalutamide resistance in castration-resistant prostate cancer cell lines. Cancer Research 73 483-489. (doi:10.1158/0008-5472.CAN-12-3630)

Lu X, Xiao L, Wang L \& Ruden DM 2012 Hsp90 inhibitors and drug resistance in cancer: the potential benefits of combination therapies of Hsp90 inhibitors and other anti-cancer drugs. Biochemical Pharmacology 83 995-1004. (doi:10.1016/j.bcp.2011.11.011)

Masiello D, Cheng S, Bubley GJ, Lu ML \& Balk SP 2002 Bicalutamide functions as an androgen receptor antagonist by assembly of a transcriptionally inactive receptor. Journal of Biological Chemistry 277 26321-26326. (doi:10.1074/jbc.M203310200)

Maughan BL \& Antonarakis ES 2015 Androgen pathway resistance in prostate cancer and therapeutic implications. Expert Opinion on Pharmacotherapy 16 1521-1537. (doi:10.1517/14656566.2015. 1055249)

Nadiminty N, Tummala R, Liu C, Yang J, Lou W, Evans CP \& Gao AC 2013 $\mathrm{NF}-\kappa \mathrm{B} 2 / \mathrm{p} 52$ induces resistance to enzalutamide in prostate cancer: role of androgen receptor and its variants. Molecular Cancer Therapeutics 12 1629-1637. (doi:10.1158/1535-7163.MCT-13-0027)

Ochel HJ \& Gademann G 2006 In vitro combined modality treatment of prostate carcinoma cells with 17-(allylamino)-17-demethoxygeldanamycin and ionizing radiation. Anticancer Research 26 2085-2091.

Pratt WB \& Toft DO 1997 Steroid receptor interactions with heat shock protein and immunophilin chaperones. Endocrine Reviews 18 306-360.

Ramanathan RK, Egorin MJ, Erlichman C, Remick SC, Ramalingam SS, Naret C, Holleran JL, TenEyck CJ, Ivy SP \& Belani CP 2010 Phase I pharmacokinetic and pharmacodynamic study of 17-dimethylaminoethylamino-17-demethoxygeldanamycin, an inhibitor of heatshock protein 90, in patients with advanced solid tumors. Journal of Clinical Oncology 28 1520-1526. (doi:10.1200/JCO.2009.25.0415)

Robinson D, Van Allen EM, Wu YM, Schultz N, Lonigro RJ, Mosquera JM, Montgomery B, Taplin ME, Pritchard CC, Attard G et al. 2015 Integrative clinical genomics of advanced prostate cancer. Cell $\mathbf{1 6 1}$ 1215-1228. (doi:10.1016/j.cell.2015.05.001)

Rossi S, Graner E, Febbo P, Weinstein L, Bhattacharya N, Onody T, Bubley G, Balk S \& Loda M 2003 Fatty acid synthase expression defines distinct molecular signatures in prostate cancer. Molecular Cancer Research $\mathbf{1}$ 707-715.

Samuel TA, Sessa C, Britten C, Milligan KS, Mita MM, Banerji U, Pluard TJ, Stiegler P, Quadt C \& Shapiro G 2010 AUY922, a novel HSP90 inhibitor: final results of a first-in-human study in patients with advanced solid malignancies. ASCO Meeting Abstracts 282528.

Scher HI, Beer TM, Higano CS, Anand A, Taplin ME, Efstathiou E, Rathkopf D, Shelkey J, Yu EY, Alumkal J et al. 2010 Antitumour activity of MDV3100 in castration-resistant prostate cancer: a phase 1-2 study. Lancet 375 1437-1446. (doi:10.1016/S0140-6736(10)60172-9)

Schiewer MJ, Augello MA \& Knudsen KE 2012 The AR dependent cell cycle: mechanisms and cancer relevance. Molecular and Cellular Endocrinology 352 34-45. (doi:10.1016/j.mce.2011.06.033)

Schmidt D, Wilson MD, Spyrou C, Brown GD, Hadfield J \& Odom DT 2009 ChIP-seq: using high-throughput sequencing to discover protein-DNA interactions. Methods 48 240-248. (doi:10.1016/j.ymeth. 2009.03.001) 
Shafi AA, Cox MB \& Weigel NL 2013 Androgen receptor splice variants are resistant to inhibitors of Hsp90 and FKBP52, which alter androgen receptor activity and expression. Steroids $\mathbf{7 8}$ 548-554. (doi:10.1016/ j.steroids.2012.12.013)

Solit DB, Zheng FF, Drobnjak M, Munster PN, Higgins B, Verbel D, Heller G, Tong W, Cordon-Cardo C, Agus DB et al. 2002 17-Allylamino17-demethoxygeldanamycin induces the degradation of androgen receptor and HER-2/neu and inhibits the growth of prostate cancer xenografts. Clinical Cancer Research 8 986-993.

Solit DB, Ivy SP, Kopil C, Sikorski R, Morris MJ, Slovin SF, Kelly WK, DeLaCruz A, Curley T, Heller G et al. 2007 Phase I trial of 17-allylamino-17-demethoxygeldanamycin in patients with advanced cancer. Clinical Cancer Research 13 1775-1782. (doi:10.1158/10780432.CCR-06-1863)

Sun S, Sprenger CC, Vessella RL, Haugk K, Soriano K, Mostaghel EA, Page ST, Coleman IM, Nguyen HM, Sun H et al. 2010 Castration resistance in human prostate cancer is conferred by a frequently occurring androgen receptor splice variant. Journal of Clinical Investigation 120 2715-2730. (doi:10.1172/JCI41824)

Swinnen JV, Van Veldhoven PP, Esquenet M, Heyns W \& Verhoeven G 1996 Androgens markedly stimulate the accumulation of neutral lipids in the human prostatic adenocarcinoma cell line LNCaP. Endocrinology 137 4468-4474.

Swinnen JV, Heemers H, van de Sande T, de Schrijver E, Brusselmans K, Heyns W \& Verhoeven G 2004 Androgens, lipogenesis and prostate cancer. Journal of Steroid Biochemistry and Molecular Biology 92 273-279. (doi:10.1016/j.jsbmb.2004.10.013)

Tran C, Ouk S, Clegg NJ, Chen Y, Watson PA, Arora V, Wongvipat J, SmithJones PM, Yoo D, Kwon A et al. 2009 Development of a secondgeneration antiandrogen for treatment of advanced prostate cancer. Science 324 787-790. (doi:10.1126/science.1168175)

Trepel J, Mollapour M, Giaccone G \& Neckers L 2010 Targeting the dynamic HSP90 complex in cancer. Nature Reviews. Cancer 10 537-549. (doi:10.1038/nrc2887)

Tyrrell CJ, Iversen P, Tammela T, Anderson J, Bjork T, Kaisary AV \& Morris T 2006 Tolerability, efficacy and pharmacokinetics of bicalutamide 300 $\mathrm{mg}, 450 \mathrm{mg}$ or $600 \mathrm{mg}$ as monotherapy for patients with locally advanced or metastatic prostate cancer, compared with castration. BJU International 98 563-572. (doi:10.1111/j.1464-410X.2006.06275.x)

Vanaja DK, Mitchell SH, Toft DO \& Young CY 2002 Effect of geldanamycin on androgen receptor function and stability. Cell Stress \& Chaperones 7 55-64. (doi:10.1379/1466-1268(2002)007< 0055:EOGOAR > 2.0.CO;2)

Vandesompele J, De Preter K, Pattyn F, Poppe B, Van Roy N, De Paepe A \& Speleman F 2002 Accurate normalization of real-time quantitative RT-PCR data by geometric averaging of multiple internal control genes. Genome Biology 3 RESEARCH0034. (doi:10.1186/gb-2002-3-7research0034)

Veldscholte J, Berrevoets CA, Brinkmann AO, Grootegoed JA \& Mulder E 1992 Anti-androgens and the mutated androgen receptor of LNCaP cells: differential effects on binding affinity, heat-shock protein interaction, and transcription activation. Biochemistry 31 2393-2399. (doi:10.1021/bi00123a026)

Wang Q, Li W, Zhang Y, Yuan X, Xu K, Yu J, Chen Z, Beroukhim R, Wang H, Lupien $\mathrm{M}$ et al. 2009 Androgen receptor regulates a distinct transcription program in androgen-independent prostate cancer. Cell 138 245-256. (doi:10.1016/j.cell.2009.04.056)

Whitesell L, Bagatell R \& Falsey R 2003 The stress response: implications for the clinical development of hsp90 inhibitors. Current Cancer Drug Targets 3 349-358. (doi:10.2174/1568009033481787)

Williams CR, Tabios R, Linehan WM \& Neckers L 2007 Intratumor injection of the Hsp90 inhibitor 17AAG decreases tumor growth and induces apoptosis in a prostate cancer xenograft model. Journal of Urology 178 1528-1532. (doi:10.1016/j.juro.2007.05.120)

Workman P, Burrows F, Neckers L \& Rosen N 2007 Drugging the cancer chaperone HSP90: combinatorial therapeutic exploitation of oncogene addiction and tumor stress. Annals of the New York Academy of Sciences 1113 202-216. (doi:10.1196/annals.1391.012)

Zou J, Guo Y, Guettouche T, Smith DF \& Voellmy R 1998 Repression of heat shock transcription factor HSF1 activation by HSP90 (HSP90 complex) that forms a stress-sensitive complex with HSF1. Cell 94 471-480. (doi:10.1016/S0092-8674(00)81588-3)

Received in final form 30 June 2015

Accepted 14 July 2015

Made available online as an Accepted Preprint

17 July 2015
(C) 2015 Society for Endocrinology Printed in Great Britain 